\title{
Homicídios do Brasil na última década: uma revisão integrativa
}

\author{
Homicides in Brazil in the last decade: an integrative review
}

André Luiz Sá de Oliveira (https://orcid.org/0000-0002-2483-550X) ${ }^{1}$

Carlos Feitosa Luna (https://orcid.org/0000-0001-9277-4086) ${ }^{1}$

Maria Gabriella Pacheco da Silva (https://orcid.org/0000-0002-2275-4992) ${ }^{2}$

${ }^{1}$ Instituto Aggeu Magalhães, Fundação Oswaldo Cruz. Av. Professor Moraes Rego s/n, Campuz UFPE, Cidade Universitária. 50740-465 Recife PE Brasil. andre.sa@cpqam.fiocruz.br ${ }^{2}$ Centro Integrado Amaury de Medeiros, Universidade de Pernambuco. Recife PE Brasil.

\begin{abstract}
Homicide is the most serious form of violence with a negative impact on the population. It is broadly studied in the scientific field and disseminated in print and in the virtual media. The scope of this article is to locate papers in national and international journals, seeking the synthesis of knowledge and the incorporation of the applicability of the results of significant studies. It involved an integrative review of the SciELO, PubMed and LILACS databases of articles published between 2006 and 2016. The following key words were researched: Homicide and Brazil. The publications were selected by the title, abstract and methodology. For homicide and health studies in Brazil, 427 papers were found, of which 98 were selected. There were publications with emphasis on the national scenario, followed by the state of São Paulo and Pernambuco. The quantitative study was the most used, with collection of secondary data. The papers dealt with homicides in the population in general (48\%), Femicide (14.3\%) and Social Determinants (7.1\%). The Brazilian scientific production on homicide and health is on the increase. It is important that researchers, analysts and editors turn their attention to the development of papers in this area, aiming to improve the quality of published articles.
\end{abstract}

Key words Homicide, Violence, Public Health, Research
Resumo O homicídio é a forma mais grave de violência com impacto negativo na população. Amplamente estudado no campo científico e divulgado por meios impressos e virtuais. O objetivo deste artigo é resgatar artigos de periódicos nacionais e internacionais, buscando a sintese do conhecimento e a incorporação da aplicabilidade de resultados de estudos significativos. Revisão integrativa a partir da plataforma SciELO, PubMed e LILACS dos artigos publicados entre 2006 e 2016. Utilizaram-se os descritores: Homicídio e Brasil. Selecionaram-se os artigos através da leitura do título, resumo e metodologia. Foram encontrados 427 artigos, dos quais 98 se referiam a estudos de homicídios e saúde no Brasil. Verificou-se publicações com destaque para o cenário nacional, seguido do estado de São Paulo e Pernambuco. $O$ estudo quantitativo foi o mais utilizado, com a coleta através de dados secundários. Os artigos abordaram os homicídios na população em geral (48\%), Feminicídio (14,3\%) e Determinantes Sociais (7,1\%). A produção científica brasileira em homicídios e saúde se encontra em fase de ascensão. É importante que os pesquisadores, analistas e editores voltem a atenção para o desenvolvimento de trabalhos no âmbito desse tema, objetivando aprimorar a qualidade dos artigos publicados.

Palavras-chave Homicídio, Violência, Saúde Pública, Pesquisa 


\section{Introdução}

A violência é tida como um fenômeno extremamente difuso e complexo cuja definição não pode ter exatidão científica, uma vez que é uma questão de apreciação, podendo ser influenciada pela cultura e submetida a uma contínua revisão na medida em que os valores e as normas sociais evoluem ${ }^{1}$.

No campo da Saúde, o tema da violência é entendido através de duas vertentes: uma explicativa, partindo de uma reflexão filosófica e teórica; outra operacional que se fundamenta na observação dos transtornos biológicos, emocionais e físicos que sua dinâmica provoca no bem-estar e na qualidade de vida das pessoas ${ }^{2}$.

A Organização Mundial de Saúde (1996) reconheceu a violência como um dos principais problemas mundiais de saúde pública. Essa afirmação foi baseada em dados que mostram o aumento da incidência de lesões intencionais em todos os grupos etários e de gênero. A abordagem da análise de violência provoca danos à saúde da população, produzindo impactos na mortalidade, na morbidade e nos custos para o setor, sejam esses decorrentes do tratamento e reabilitação das vítimas como também dos anos potenciais de vidas perdidos.

Os homicídios representam a expressão mais grave de violência e têm grande impacto negativo sobre a população, causando medo, insegurança e alterando o comportamento, tanto no trato interpessoal, quanto no desenho paisagístico das cidades, comprometendo a cidadania e os direitos humanos ${ }^{3}$.

Em uma perspectiva evolutiva dos trabalhos científicos, Minayo ${ }^{4}$ realizou um levantamento acerca de materiais produzidos no campo da saúde sobre a investigação da violência no Brasil, e encontrou os seguintes achados: os estudos epidemiológicos tiveram início na década de 70 e tiveram sua expansão na década de 80 . Segundo a autora, a maioria dos trabalhos abordavam a violência relacionada aos acidentes de trabalho e de trânsito, seguido dos suicídios e causas externas em geral ${ }^{4}$.

Na década de 90, destaca-se o grande incremento da produção de trabalhos, justificado pela evolução tecnológica. Nesse período, o maior número de textos trata da categoria causas externas, estando relacionada à relevância e preocupação do aumento da criminalidade ${ }^{5}$.

No período de 2000-2005, sobressai a tendência de análise espacial da mortalidade, atrelada às desigualdades na ocupação dos centros urbanos.
Nesse sentido estão os homicídios na população masculina e jovem, reiterando a influência dos determinantes sociais sobre a violência ${ }^{5}$.

As pesquisas realizadas ao longo das décadas enfatizam as magnitudes e preocupações do setor saúde acerca dos homicídios. Entendeu-se, contudo, o pluralismo da temática, necessário para a compreensão da manifestação desse problema nos campos sociais, políticos, econômicos e da saúde.

Essas considerações justificam o interesse em realizar uma revisão integrativa sobre a produção científica dos estudos em homicídios no Brasil, publicados na literatura brasileira e internacional, para a interpretação do conhecimento produzido na área da saúde pública com o intuito de estimular o desenvolvimento de novas investigações no tema.

Baseado nos estudos anteriores e considerando que os homicídios são a primeira causa de morte nas camadas jovens da população, superando todas as demais causas ${ }^{6}$, o presente artigo teve como objetivo de fazer um resgate dos manuscritos publicados no período de 2006-2016, proporcionando a síntese do conhecimento e a incorporação da aplicabilidade de resultados de estudos significativos.

\section{Métodos}

Para o levantamento dos estudos sobre homicídios e saúde pública no Brasil foi realizada uma revisão integrativa de literatura fundamentada nos estudos de Souza et al. ${ }^{7}$, Whittemore e Knafl ${ }^{8}$, e Broome 9 . A busca pelos artigos foi realizada nas plataformas SciELO (Scientific Eletronic Library Online), PubMed (Public Medline) e LILACS (Literatura Latino-Americana em Ciências de Saúde), considerando os artigos publicados entre os anos de 2006 e 2016. A escolha dessas bases de dados se deu ao fato de as mesmas indexarem as principais revistas nacionais e internacionais no campo da saúde pública.

$\mathrm{O}$ método constituiu um instrumento da Prática Baseada em Evidências (PBE), que envolveu a definição do problema, identificação das informações necessárias, condução da busca de estudos na literatura e sua avaliação crítica, identificação da aplicabilidade dos dados oriundos das publicações e a determinação da sua utilização ${ }^{7}$. Buscou-se identificar uma temática que fornecesse um maior embasamento ao estudo sobre violência e saúde no âmbito das contribuições dos estudos sobre homicídios no Brasil, com a 
finalidade de melhor compreensão desse evento complexo. Portanto, o presente estudo buscou fazer um diagnóstico situacional dos estudos de homicídios e saúde no Brasil e que contribuições esses estudos têm trazido para uma melhor interpretação do conhecimento produzido na última década.

A busca pela literatura ocorreu, concomitantemente, nos meses de maio, junho e julho de 2017, com o intuito de garantir uma busca ampla de evidências. Para o levantamento dos artigos, utilizou-se as palavras-chave "homicídio" e "Brasil", e suas combinações na língua portuguesa e inglesa.

Os critérios de inclusão foram as publicações em qualquer idioma, em periódicos nacionais e internacionais, no período de $1^{\circ}$ de janeiro de 2006 a 31 de dezembro de 2016 que apresentassem a temática de homicídios no território nacional. Foram excluídos artigos publicados no período anterior ao estabelecido, revisões de literaturas e estudos de homicídios fora do Brasil. Artigos em duplicidade foram contabilizados uma única vez.

Para sumarização das informações foi construído um banco de dados com a finalidade de garantir que a totalidade de dados relevantes fosse extraída, reduzindo o risco de erros, observando a qualidade na checagem das informações e servindo como registro de coleta de dados contendo as variáveis propostas e validadas pelo modelo Ursi ${ }^{10}$. A base de dados permitiu obter informações sobre a identificação do artigo e autores, fonte de localização, objetivos, delineamento e local do estudo, coerência metodológica, método de coleta, entre outros.

As análises e geração dos resultados ocorreram da seguinte forma: distribuição das publicações nas plataformas pesquisadas; descrição dos dados referentes ao idioma e ano de publicação; identificação das instituições e grupos de pesquisa/estudos e o estado nos quais se localizam, além da identificação de regiões com ausência de estudos; tipo do periódico escolhido para publicação do trabalho e o seu fator Qualis para a área da saúde coletiva; titulação e profissão dos autores.

No tocante às características metodológicas dos artigos, os mesmos foram analisados de acordo com o delineamento, desenho, método de coleta, características da amostra, população alvo e identificação da área de estudo. Questões éticas também foram analisadas.

Posteriormente, os artigos receberam um código identificador único e as informações inseridas no banco de dados. As análises foram realizadas através do método da estatística descritiva, que incluiu a distribuição de frequência absoluta e relativa. Para testar associação entre as variáveis foi aplicado o teste exato de Fisher com todas conclusões tomadas ao nível de significância de 5\%. Para verificar a tendência linear das sérias temporais, foram estimados modelos de regressão linear simples. Tais resultados foram ilustrados em forma de gráficos e tabelas.

Por fim, de acordo com os achados, foi discutido o perfil epidemiológico das ocorrências de homicídios no país, identificando características como sexo, faixa etária, nível socioeconômico das vítimas, além de uma abordagem da determinação social da violência homicida.

A construção do banco de dados, assim como as análises e geração dos resultados foram realizadas no software Microsoft Excel 2013, QGIS 2.18 e SPSS versão 20.

\section{Resultados e discussão}

Os resultados e discussões foram baseados nesse levantamento e fazendo uso de alguns estudos complementares tendo como fonte de dados relevantes.

Foram encontrados 427 artigos e com base na leitura dos títulos, resumos e metodologia, foram selecionadas 98 publicações que se referiam a estudos de homicídios e saúde nos seus diversos aspectos e que tratavam da realidade brasileira.

Dos 98 artigos selecionados, todos apresentaram rigor metodológico e clareza em seus objetivos, possibilitando o fácil entendimento do leitor. Foram encontrados 23 artigos somente na base de dados SciELO (23,5\%), 12 somente na PubMed (12,2\%), e apenas 5 publicações na LILACS $(5,1 \%)$. Simultaneamente encontrou-se 21 manuscritos na SciELO e LILACS (21,4\%), 12 na SciELO e PubMed (12,2\%) e 25 publicações na SciELO, PubMed e LILACS (25,5\%). Nenhuma publicação foi encontrada simultaneamente nas bases LILACS e PubMed.

Dentre os manuscritos publicados, $73 \%$ foram redigidos em língua portuguesa e $27 \%$ em língua inglesa. $\mathrm{O}$ número de artigos publicados na última década apresentou oscilação no período com tendência de crescimento. Apesar do quantitativo publicado por ano ser relativamente baixo (Figura 1A), não houve significância estatística $(\beta=0,418 ; p=0,160)$. Deve ser levada em consideração a premissa do aumento da violência que, segundo Schraiber et al. ${ }^{5}$, é perpassada pelas desigualdades sociais, ausência de políticas 
públicas integradas e condizentes com as necessidades da população em relação à saúde, renda, moradia e segurança.

O ano de 2014 destacou-se como o período com o maior número de publicações marcado pela exploração dos estudos ecológicos e transversais. No período anterior ao analisado, os estudos em homicídios resumiam-se em estatísticas descritivas e abordagens qualitativas baseadas em estudos de caso ${ }^{5}$.

Estudos envolvendo homicídios na população geral apresentaram variabilidade no período, sem tendência (Figura $1 B$ ) e não significativa ( $\beta$ $=0,000 ; \mathrm{p}=1,000)$. $\mathrm{E}$ os artigos com abordagem qualitativa (Figura 1C) e quantitativa (Figura 1D) também apresentaram flutuações no decorrer do período, com tendência de crescimento, porém sem significância estatística $(\beta=0,164 ; \mathrm{p}$ $=0,227)$ e $(\beta=0,255 ; \mathrm{p}=0,232)$ respectivamente.

Outro ponto forte encontrado nas publicações foi a questão do feminicídio, correspondendo a 14,3\% dos artigos encontrados. As publicações envolvendo essa temática apresentaram oscilações no período analisado, com tendência de crescimento (Figura 1E), mas sem significância $(\beta=0,255 ; p=0,132)$. De acordo com o Atlas da Violência 2017, no ano de 2015, 4.621 mulheres foram assassinadas no Brasil, o que corresponde a uma taxa de 4,5 mortes para cada 100 mil mulheres. Desse número, $65,3 \%$ das mulheres assassinadas eram negras, na evidência de que a combinação entre desigualdade de gênero e racismo é extremamente perversa e configura variável fundamental para compreendermos a violência letal contra a mulher no país ${ }^{11}$.

No tocante à área de estudo, foram detectadas pesquisas sobre homicídios realizadas em todas as regiões do Brasil, porém nem todos os estados. Identificou-se estudos em 17 das 27 unidades da federação. $\mathrm{O}$ desenvolvimento em pesquisas no âmbito nacional destacou-se como objeto de estudo com 20,4\% dos artigos, seguido pela as regiões Sudeste $(30,6 \%)$, Nordeste $(26,5 \%)$, Sul $(16,3 \%)$, Centro-Oeste $(5,1 \%)$ e Norte (1\%). Em nível estadual, o estado de São Paulo apresentou o maior percentual de publicações $(17,3 \%)$, onde a maior parte delas foram produzidas pelo Núcleo de Estudos de Violência da Universidade de São Paulo (USP). O Instituto de Medicina Integral Professor Fernando Figueira (IMIP), localizado no estado de Pernambuco, também se destacou na temática com ênfase em pesquisas em sua capital (10,2\%), além de artigos publicados pelo Núcleo de Saúde Coletiva da UFBA situado na Bahia $(9,2 \%)$ e o estado do Paraná $(8,2 \%)$, onde tiveram destaque os manuscritos produzidos pelo Grupo de Pesquisas em Saúde Coletiva da Universidade Estadual Oeste do Paraná, Departamento de Vigilância em Saúde da Secretaria Municipal de Saúde de Curitiba e Universidade Estadual de Maringá (Figura 2) (Tabela 1).

Embora exista um número reduzido de pesquisas realizadas nos estados localizados no Norte-Nordeste e Centro-Oeste, com exceção de Pernambuco, Bahia, Acre e Distrito Federal, alguns estados brasileiros, tais como Amazonas, Rondônia, Roraima, Amapá, Pará, Tocantins, Rio Grande do Norte e Maranhão não apresentaram estudos regionalizados envolvendo as temáticas abordadas, levando à falta de conhecimento da realidade local. Silveira e $\mathrm{Zago}^{12}$ afirmam que se for levado em conta que o Brasil possui grandes desigualdades sociais e econômicas entre estados e regiões, a aplicação de resultados de pesquisa oriundos de instituições ou centros mais desenvolvidos economicamente fica comprometida em regiões menos favorecidas e vice-versa, devido aos recursos tecnológicos e qualificação profissional existente.

Quanto à publicação, 79,6\% dos artigos foram publicados em periódicos nacionais e 20,4\% em periódicos internacionais. Observou-se o maior número de artigos sobre homicídios na Revista Ciência \& Saúde Coletiva (10,2\%). Tal fato se explica por se tratar de um periódico específico voltado para Saúde Pública, Epidemiologia e Controle de Agravos à Saúde. Cadernos de Saúde Pública $(8,2 \%)$, Revista Brasileira de Epidemiologia (8,2\%), Revista de Saúde Pública $(8,2 \%)$, Epidemiologia e Serviços de Saúde $(7,1 \%)$ e Revista Panamericana de Salud Pública $(6,1 \%)$ vieram em seguida apresentando também um considerado percentual de publicações na área de homicídios.

Em relação ao fator Qualis dos periódicos para a área da Saúde Coletiva, 26,5\% dos artigos foram publicados em revistas com Qualis B1, $22,4 \%$ em A2, $16,3 \%$ em B2, 10,2\% em B3, 3,1\% em B4, $2 \%$ em A1 e $2 \%$ em B5. Por fim, $17,3 \%$ dos artigos foram publicados em revistas sem qualis para saúde coletiva (Figura 3) (Tabela 1).

Quanto à titulação, a maioria dos autores possui título de doutor $(71,4 \%)$ ou mestrado $(19,4 \%)$ (Tabela 1). Dentre os doutores e mestres, a maioria são docentes, pesquisadores e discentes. E no tocante à profissão, há participação de diversos tipos de profissionais, tais como: médicos, enfermeiros, psicólogos, fisioterapeutas, geógrafos e promotores de justiça. Percebeu-se nos artigos a questão da parceria entre os profis- 
(A) Publicações por Ano

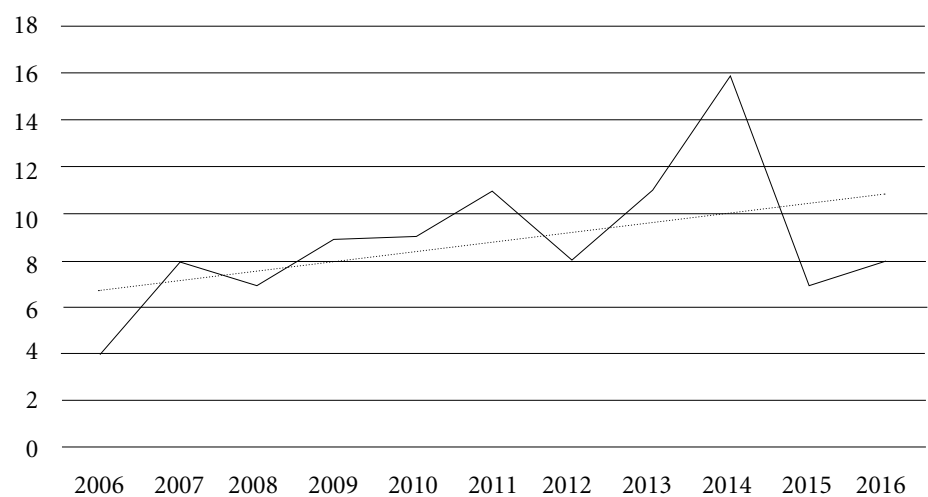

(B) Homicídio na População Geral

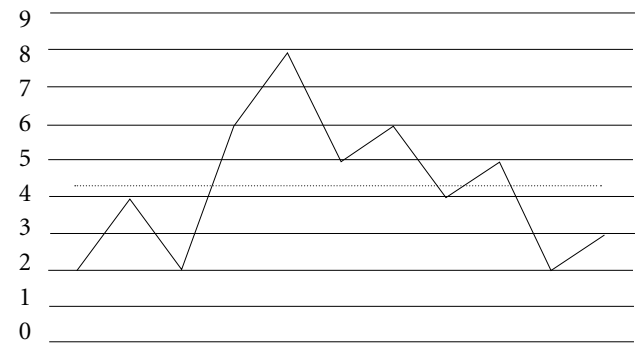

20062007200820092010201120122013201420152016
(C) Abordagem Qualitativa

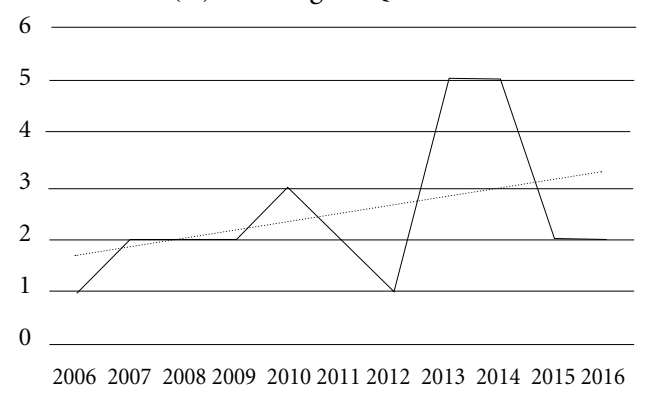

(E) Abordagem em Feminicídios

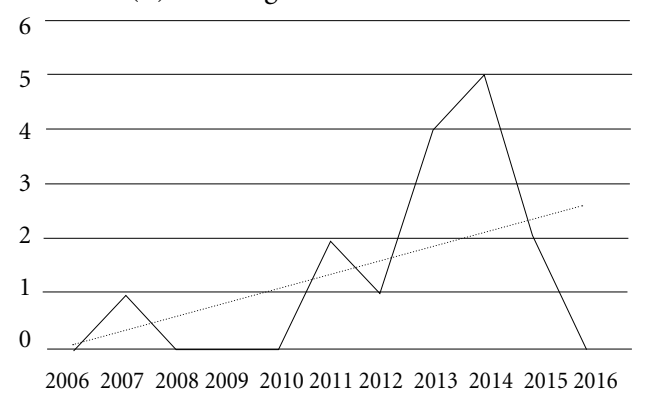

Figura 1. Série temporal das publicações em homicídios na última década de acordo com as abordagens: (A) Total de Publicações por ano, (B) População Geral, (C) Pesquisa Qualitativa, (D) Pesquisa Quantitativa, e (E) Feminicídios.

sionais da saúde e profissionais de outras áreas, dando ênfase ao desenvolvimento de pesquisas em equipe multidisciplinar, compartilhando conhecimento e experiências no ramo da saúde pública para melhoria das ações de vigilância e controle epidemiológico.

Ao analisar o delineamento das pesquisas, a maioria das publicações envolveram uma abor- dagem quantitativa $(70,4 \%)$, enquanto o método qualitativo abarcou $27,6 \%$ dos artigos. Estudos que envolveram uma análise quanti-qualitativa representaram apenas $2 \%$ do total de manuscritos selecionados (Tabela 1).

Dentre os estudos quantitativos, o desenho mais utilizado foi o ecológico $(60,3 \%)$, seguido do estudo transversal $(27,9 \%)$ e descritivo 


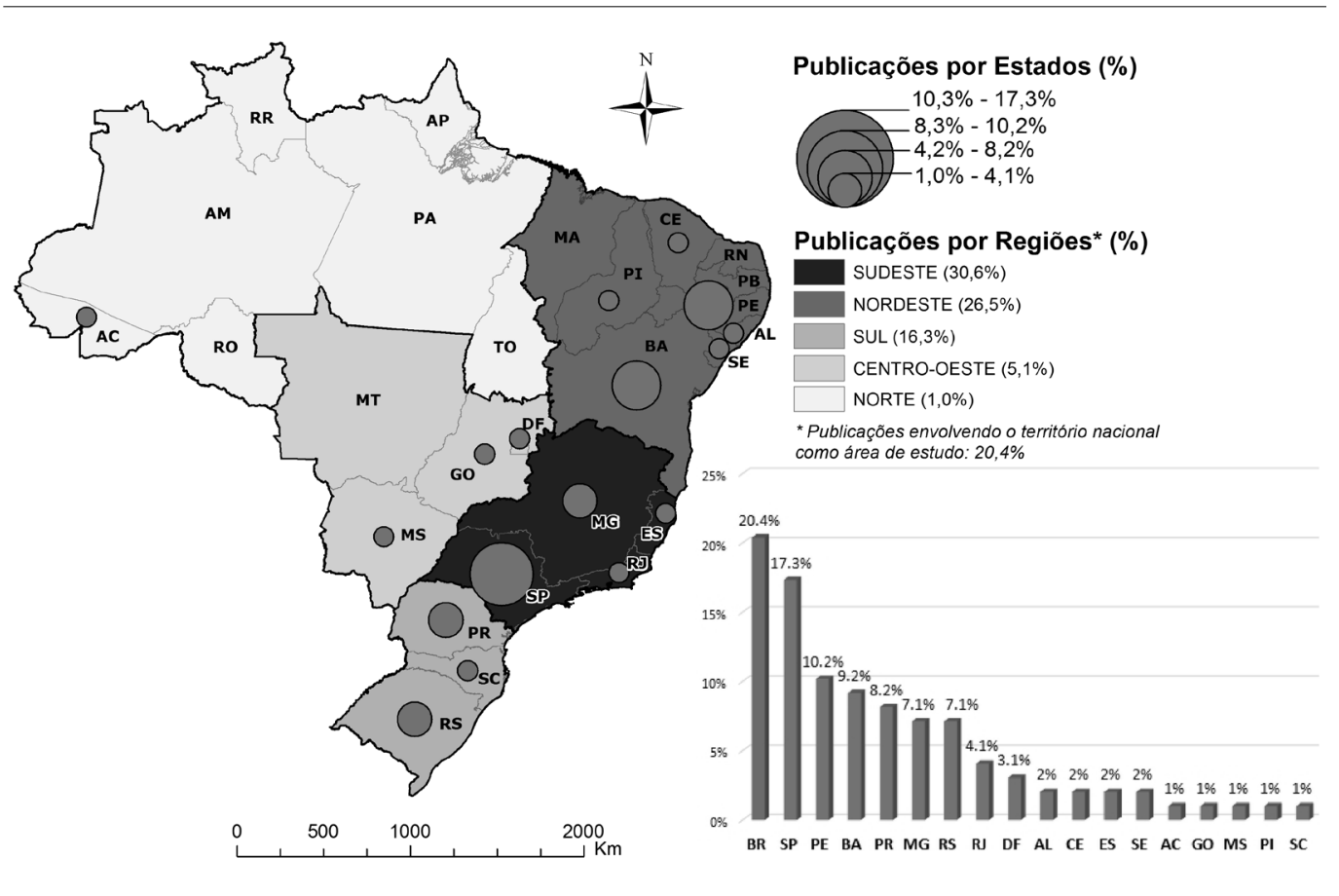

Figura 2. Panorama das Publicações por estados e regiões do Brasil, segundo área de estudo.

$(8,8 \%)$. Outros estudos epidemiológicos com abordagem quantitativa foram utilizados, tais como o estudo retrospectivo $(1,5 \%)$ e série de casos $(1,5 \%)$, porém com baixa representatividade (Tabela 1).

Em relação ao método de coleta de dados, os estudos quantitativos realizaram seu levantamento através de dados secundários $(92,9 \%)$ e aplicação de questionário estruturado $(7,1 \%)$. Dentre os estudos qualitativos a utilização da entrevista semiestruturada foi a mais utilizada $(40,7 \%)$, seguido de pesquisa documental $(29,3 \%)$, reflexão teórica $(25,9 \%)$ e pesquisa etnográfica $(7,4 \%)$.

Dentre os manuscritos analisados, 65,3\% apresentaram características da amostra pesquisada. A população alvo das pesquisas envolviam a população geral $(62,8 \%)$, seguido de homicídios contra as mulheres (17\%), presidiários $(5,3 \%)$, homens $(5,3 \%)$, adolescentes $(4,3 \%)$, crianças $(3,2 \%)$ e negros $(2,1 \%)$.

A maioria dos estudos relataram sobre a questão da ética (95,6\%). Tal resultado é fruto da implantação da Resolução 466/2012 que determina que devem passar por uma avaliação ética todas as pesquisas que envolvam seres humanos. Os demais 4,4\% das publicações não relataram nenhuma consideração ética.

A pesquisa revelou que o padrão de homicídios no Brasil não sofreu grandes modificações no período. Com taxa de 21,2 homicídios por cada 100 mil habitantes, ocupou a $10^{\text {a }}$ posição em um ranking de 100 países analisados no ano de $2014^{13}$. Essa taxa é superior à taxa média global e também maior que muitos países no ano de referência, como Islândia, Japão, República da Coreia, Luxemburgo, Escócia, Inglaterra e Gales. O Brasil registrou, no período de 2011 a 2015, em número absolutos, mais vítimas de mortes violentas intencionais (ou pessoas assassinadas) em 5 anos do que a Guerra na Síria. No mesmo período, foram contabilizadas 256.124 pessoas mortas nos conflitos da Síria, enquanto no Brasil o número de vítimas por homicídio chegou a 279.567 pessoas $^{14}$.

Jovens do sexo masculino, na faixa etária de 15 a 29 anos que residem nas periferias das cidades ou favelas fazem parte do perfil epidemiológico da violência homicida no país. Essa informação foi constatada em 54,1\% dos manuscritos pesquisados.

Outra categoria atingida pela violência homicida abordada nas pesquisas retratou a questão dos determinantes sociais $(7,1 \%)$. No discurso da violência e saúde, os determinantes sociais envolvem todos os fatores socioeconômicos, culturais, étnico, racial, psicológico e comportamental. Os fatores socioeconômicos refletem nos modos de vida das pessoas, onde o cidadão e a coletividade 
Tabela 1. Principais características das Publicações no período 2006-2016, segundo origem do periódico.

\begin{tabular}{|c|c|c|c|c|c|c|c|}
\hline & \multicolumn{6}{|c|}{ Periódico } & \multirow{3}{*}{$\mathbf{p}$} \\
\hline & \multicolumn{2}{|c|}{ Total } & \multicolumn{2}{|c|}{ Nacional } & \multicolumn{2}{|c|}{ Internacional } & \\
\hline & $\mathbf{N}$ & $\%$ & $\mathbf{N}$ & $\%$ & $\mathrm{~N}$ & $\%$ & \\
\hline \multicolumn{8}{|l|}{ Qualis } \\
\hline A1 & 2 & 2 & 0 & 0 & 2 & 10,0 & \\
\hline $\mathrm{A} 2$ & 22 & 22,4 & 16 & 20,5 & 6 & 30 & \\
\hline $\mathrm{B} 1$ & 26 & 26,5 & 26 & 33,3 & 0 & 0 & \\
\hline B2 & 16 & 16,3 & 14 & 17,9 & 2 & 10 & \\
\hline B3 & 10 & 10,2 & 9 & 11,5 & 1 & 5 & \\
\hline B4 & 3 & 3,1 & 3 & 3,8 & 0 & 0 & \\
\hline B5 & 2 & 2 & 2 & 2,6 & 0 & 0 & \\
\hline Sem Qualis & 17 & 17,3 & 8 & 10,3 & 9 & 45 & $<0,001$ \\
\hline \multicolumn{8}{|l|}{ Titulação } \\
\hline Doutorado & 70 & 71,4 & 53 & 67,9 & 17 & 85,0 & \\
\hline Especialização & 1 & 1 & 1 & 1,3 & 0 & 0 & \\
\hline Graduação & 8 & 8,2 & 6 & 7,7 & 2 & 10 & \\
\hline Mestrado & 19 & 19,4 & 18 & 23,1 & 1 & 5 & 0,261 \\
\hline \multicolumn{8}{|l|}{ Abordagem } \\
\hline Qualitativa & 27 & 27,6 & 23 & 29,5 & 4 & 20 & \\
\hline Quantitativa & 69 & 70,4 & 53 & 67,9 & 16 & 80 & \\
\hline Ambas & 2 & 2 & 2 & 2,6 & 0 & 0 & 0,632 \\
\hline \multicolumn{8}{|l|}{ Desenho de estudo } \\
\hline Sem informação & 24 & 24,5 & 21 & 26,9 & 3 & 15 & \\
\hline Descritivo & 6 & 6,1 & 3 & 3,8 & 3 & 15 & \\
\hline Ecológico & 43 & 43,9 & 36 & 46,2 & 7 & 35 & \\
\hline Estudo de Caso & 4 & 4,1 & 3 & 3,8 & 1 & 5 & \\
\hline Retrospectivo & 1 & 1 & 1 & 1,3 & 0 & 0 & \\
\hline Série de Casos & 1 & 1 & 1 & 1,3 & 0 & 0 & \\
\hline Transversal & 19 & 19,4 & 13 & 16,7 & 6 & 30 & 0,291 \\
\hline \multicolumn{8}{|l|}{ Região } \\
\hline Nacional & 20 & 20,4 & 15 & 19,2 & 5 & 25 & \\
\hline Centro-Oeste & 5 & 5,1 & 5 & 6,4 & 0 & 0 & \\
\hline Nordeste & 26 & 26,5 & 23 & 29,5 & 3 & 15 & \\
\hline Norte & 1 & 1 & 1 & 1,3 & 0 & 0 & \\
\hline Sudeste & 30 & 30,6 & 21 & 26,9 & 9 & 45 & \\
\hline Sul & 16 & 16,3 & 13 & 16,7 & 3 & 15 & 0,502 \\
\hline
\end{tabular}

devem ser compreendidos como integrantes de uma totalidade determinada pelo modo de produção, pela economia adotada e pelos processos de reprodução social ${ }^{15}$. Segundo Garbois et al. ${ }^{15}$, o desenvolvimento e expansão capitalista evidenciado pela globalização e avanços tecnológicos não contribuiu para a redução das desigualdades e das injustiças sociais.

A análise das publicações em homicídios mostrou forte relação com as condições de vida, expondo as pessoas a um nível de vulnerabilidade elevado justificado pela falta de oportunidade social. Tais fatores ainda são agravados pelas disputas do território e tráfico de drogas.

Detectou-se um pequeno número de publicações relacionados ao uso de armas de fogo, alcoolemia, acidentes de trânsito, raça, disputas territoriais, vulnerabilidade e risco, além de homicídios de homens e jovens.

Verificou-se a incipiência de estudos associados com aborto, violação de direitos e desigualdade de gênero. A maioria dos artigos abordaram a violência física e sexual associada ao crime violento letal e intencional contra as mulheres. 


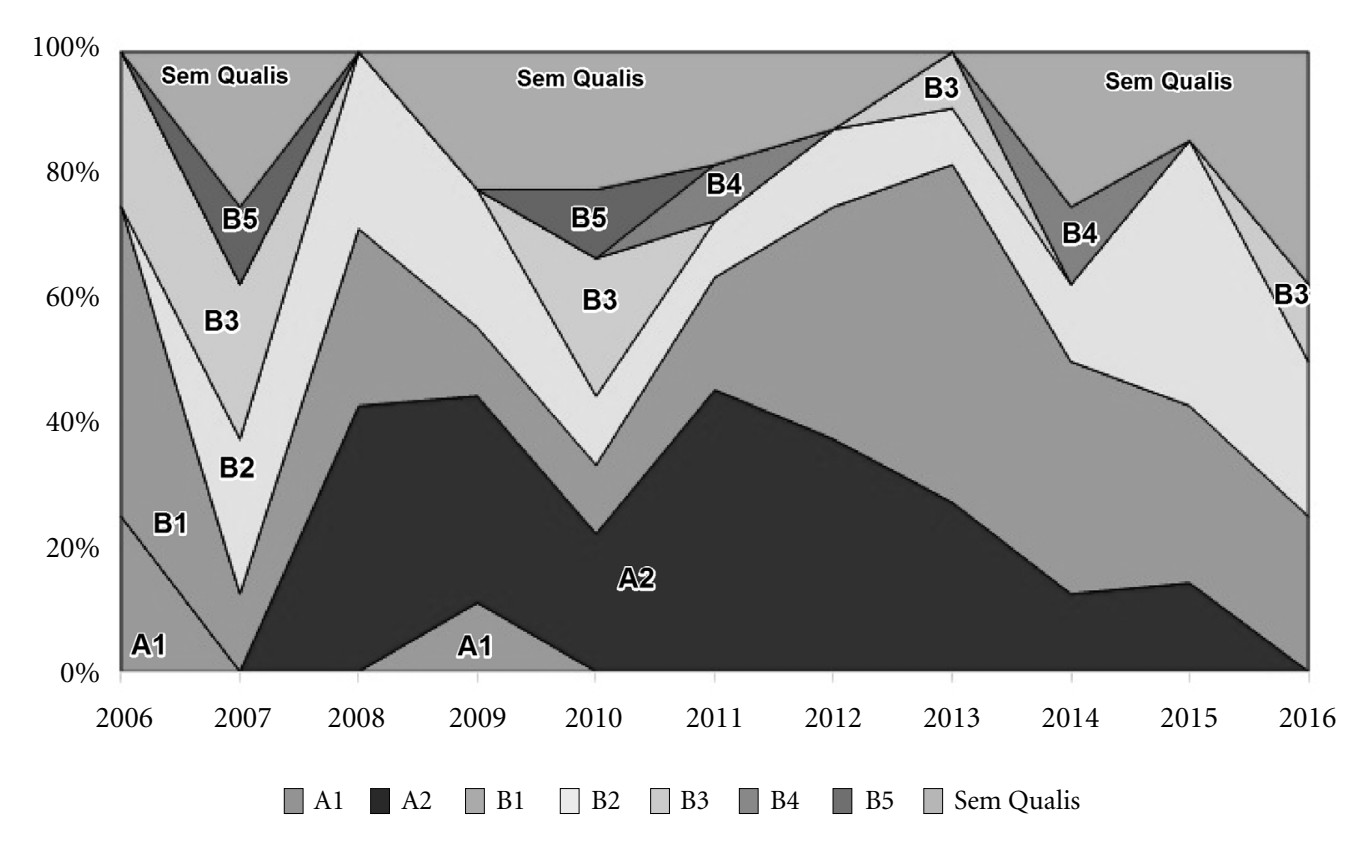

Figura 3. Evolução das Publicações em homicídios na última década classificado pelo fator Qualis.

Uma das limitações encontradas nos artigos foi a utilização de dados secundários, sendo possível a presença de viés decorrente da qualidade das informações dos bancos de dados avaliados. Outra limitação se referiu a escolha da unidade espacial de análise nos estudos ecológicos que se limitaram ao nível de município ou estado, sendo uma unidade de análise bastante extensa para agregação dos dados, ocultando a heterogeneidade dos homicídios, dificultando assim a identificação de grupos populacionais mais vulneráveis dentro do município ou estado.

\section{Conclusão}

De acordo com o que foi discutido, compreendeu-se que a produção científica brasileira em homicídios e saúde se encontra em fase de construção e ascensão. Contudo, é importante que os pesquisadores, analistas e editores voltem a atenção para o desenvolvimento de trabalhos no âmbito desse tema, objetivando o aprimoramento da qualidade dos artigos publicados.

A temática da violência, em especial os homicídios, segue demandando atenção do campo da saúde pública no que diz respeito a situação, estratégias de prevenção, controle e políticas de enfrentamento. Observou-se que não ocorreu redução dos homicídios, assumindo-se a ideia de que o setor saúde não resolve isoladamente o problema. É necessária a integração dos diversos setores da gestão pública e sociedade civil para obter melhores respostas no âmbito das políticas e serviços de saúde. Nesse sentido, vale potencializar o exercício da participação da sociedade e no controle social sobre as políticas e os serviços de saúde, direcionando as suas necessidades.

Como não existe o estabelecimento de prioridades na pesquisa em homicídios no Brasil, assimilou-se que os problemas de estudos descritos estão relacionados ao interesse particular de cada pesquisador. Frente a esse fato, sugere-se que os pesquisadores identifiquem prioridades de pesquisa em homicídios no Brasil, para que se construa o conhecimento em áreas que necessitam de embasamento científico, incentivando o desenvolvimento de estudos em regiões com carência desse tipo de estudo.

De maneira geral, os estudos de homicídios e saúde encontram-se em uma tendência de ascensão em sua produção científica. Isso demonstra que a pesquisa ainda não está consolidada, por causa da existência de lacunas na produção do conhecimento. Alguns subtemas, embora tímidos, surgiram apontando novas possibilidades de investimento intelectual com exigência na atualização metodológica e no pluralismo que o tema "homicídios e saúde pública" demanda. 


\section{Colaboradores}

ALS Oliveira, MGP Silva e CF Luna participaram da concepção, planejamento, análise, interpretação, redação final e revisão crítica do manuscrito. ALS Oliveira e MGP Silva participaram da construção do banco de dados. Todos os autores aprovaram a versão final do manuscrito e declaram ser responsáveis por todos os aspectos do trabalho, garantindo sua precisão e integralidade.

\section{Referências}

1. Ferrari IF. Agressividade e Violência. Psic Clin 2006; 18(2):49-62.

2. Minayo MCS. A violência social sob a perspectiva da saúde pública. Cad Saude Publica 1994; 10(1):7-18.

3. Guirra GCS, Souza LE, Moreau MS. Análise da distribuição espacial de homicídios na zona urbana de Ilhéus-BA. In: Semana de Geografia da UESB, Anais da Semana de Geografia, Vitória da Conquista; 2011 [acessado 2015 Ago 10]. Disponível em: http://www. uesb.br/eventos/ebg/anais/2i.pdf

4. Minayo MCS, organizadora. Bibliografia comentada da produção científica brasileira sobre violência e saúde. Rio de Janeiro: Editora Panorama, Ensp; 1990.

5. Schraiber LB, D’Oliveira AFPL, Couto MT. Violência e Saúde: estudos científicos recentes. Rev Saude Publica 2006; 40(esp.):112-120.

6. Lima RS, Paula L. organizadores. Segurança Pública e Violência: o Estado está cumprindo o seu papel? São Paulo: Contexto; 2008.

7. Souza MT, Silva MD, Carvalho R. Revisão Integrativa: o que é e como fazer. Einstein 2010; 8(1):102-106.

8. Whittemore R, Knafl K. The integrative review: update methodology. J Adv Nurs 2005; 52(5):546-553.

9. Broome ME. Integrative literature reviews for the development of concepts. In: Rodgers BL, Knafl KA, editores. Concept development in nursing: foundations, techniques and applications. Philadelphia: WB Saunders; 2000. p. 231-250.

10. Ursi ES. Prevenção de lesões de pele no perioperatório: revisão integrativa da literatura. [dissertação]. Ribeirão Preto: Universidade de São Paulo; 2005.

11. Cerqueira D, Lima RS, Bueno S, Valencia LI, Hanashiro O, Machado PHG, Lima AS. Atlas da Violência 2017 [documento na Internet]. Rio de Janeiro: Ipea, Fórum Brasileiro de Segurança Pública; 2017 [acessado 2017 Jul 3]. Disponível em: http://www.ipea.gov.br/portal/ images/170602_atlas_da_violencia_2017.pdf

12. Silveira CS, Zago MMF. Pesquisa Brasileira em Enfermagem Oncológica: Uma Revisão Integrativa. Rev Lat Am Enferm 2006; 14(4):614-619.

13. Waiselfisz JJ. Mapa da Violência 2016: Os novos padrões da violência homicida no Brasil [página na Internet]. São Paulo; 2016 [acessado 2017 Jul 1]. Disponível em: http://www.sangari.com/mapadaviolencia/

14. Brasil. Ministério da Justiça (MJ). Anuário Brasileiro de Segurança Pública 2016 [página na Internet]. Brasília; 2016 [acesso 2017 Ago 2]. Disponível em: http://www2.forumseguranca.org.br/node/26939

15. Garbois JA, Sodré F, Dalbello-Araújo M. Determinantes Sociais da Saúde: o "social” em questão. Saude Soc 2014; 23(4):1173-1182. 
